\title{
APLIKASI SISTEM PAKAR PENDETEKSI KERUSAKAN PADA SMARTPHONE MENGGUNAKAN METODE DEMPSTER SHAFER
}

\author{
Widiyanto, Liza Safitri \\ STT Indonesia Tanjungpinang \\ widiyanto@gmail.com, lizasafi3@gmail.com
}

\section{Abstract}

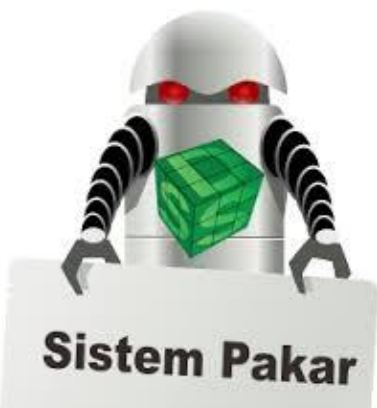

Seiring pemakaian smartphone yang semakin lama, pengguna smartphone biasanya akan menemukan gangguan berupa gejala-gejala kerusakan yang dialami smartphone mereka, baik gejala kerusakan pada software maupun hardware. Tetapi, pengguna smartphone yang tidak mengetahui penyebab kerusakan pada smartphone mereka, sehingga hal ini membuat mereka bingung karena tidak bisa mendapatkan solusi perbaikannya. Oleh karena itu, dibutuhkan sebuah aplikasi yang dapat membantu pengguna smartphone dalam mendiagnosa atau mencari kerusakan yang dialami smartphone mereka dengan lebih cepat sehingga pengguna smartphone mengetahui letak kerusakan dan mendapatkan solusi.

Berdasarkan permasalahaan yang ada, penulis melakukan analisa dan merancang sebuah sistem pakar yang dapat mengatasi masalah yang dialami pengguna smartphone dalam mendiagnosa atau mencari kerusakan smartphone yang bervariasi. Software yang yang digunakan dalam pembangunan sistem pakar ini adalah Delphi dan Microsoft Office Access 2007 sebagai database. Adapun metodologi yang digunakan untuk pengembangan sistem pakar ini adalah metodologi waterfall. Sedangkan metode sistem pakar yang digunakan adalah metode dempster shafer yaitu teori matematika pembuktian berdasarkan fungsi kepercayaan dan pemikiran yang masuk akal.

Sehingga didapatkanlah sebuah sistem pakar yang mengandung ilmu pengetahuan tentang kerusakan smartphone. Sistem pakar ini dapat membantu pengguna smartphone dalam melakukan diagnosa dan pencarian terhadap jenis kerusakan smartphone secara umum melalui pemilihan gejala kerusakan yang terjadi pada smartphone mereka. Dengan bantuan sistem pakar ini, diharapkan dapat membantu pengguna smartphone agar mendapatkan solusi yang tepat.

Kata kunci : aplikasi, sistem pakar, diagnosa, kerusakan, smartphone, pengguna, dempster shafer.

\section{PENDAHULUAN}

\section{A. Latar Belakang Penelitian}

Seiring berjalannya waktu pemakaian smartphone yang semakin lama, biasanya pengguna smartphone akan menemukan gangguan atau gejala-gejala kerusakan pada smartphone mereka, baik gejala kerusakan pada software maupun hardware. Tetapi, pengguna smartphone yang tidak mengetahui penyebab kerusakan pada smartphone mereka, sehingga hal ini membuat mereka bingung karena tidak mengetahui apa penyebab kerusakan tersebut. 
Oleh karena itu dari permasalahan tersebut, penulis tertarik untuk membuat sebuah sistem yang berhubungan dengan masalah kerusakan smartphone, supaya permasalahan tersebut lebih mudah ditelusuri kerusakannya, dan cukup dengan menggunakan sistem maka permasalahan kerusakan smartphone dapat diketahui dan menemukan solusi untuk permasalahan kerusakan smartphone. Oleh karena itu maka penulis membuat aplikasi dengan judul "APLIKASI

\section{SISTEM PAKAR PENDETEKSI KERUSAKAN PADA SMARTPHONE} MENGGUNAKAN METODE DEMPSTER SHAFER”

\section{B. Rumusan Masalah}

1. Apa yang dibutuhkan pengguna smartphone untuk mengetahui penyebab kerusakan pada smartphone mereka?

2. Apakah dengan sistem pakar ini pengguna bisa menghemat waktu?

3. Apakah sistem pakar ini bisa mempermudah pengguna smartphone dalam hal memberikan informasi?

\section{II.KAJIAN PUSTAKA}

\section{A. Sistem Pakar}

Sistem pakar atau Expert System biasa disebut juga dengan Knowledge Based System yaitu suatu aplikasi computer yang ditujukan untuk membantu pengambilan keputusan atau pemecahan persoalan dalam bidang yang spesifik. Sistem ini bekerja dengan menggunakan pengetahuan dan metode analisis yang telah didefinisikan terlebih dahulu oleh pakar yang sesuai dengan bidang keahliannya. Sistem ini disebut sistem pakar karena fungsi dan perannya sama seperti seorang ahli yang harus memiliki pengetahuan, pengalaman dalam memecahkan suatu persoalan. Sistem biasanya berfungsi sebagai kunci penting yang akan membantu suatu sistem pendukung keputusan atau sistem pendukung eksekutif

\section{B. Kecerdasan Buatan}

Kecerdasan buatan adalah suatu ilmu yang mempelajari cara membuat komputer melakukan sesuatu seperti yang dilakukan oleh manusia (Minsky, 1989). Definisi lain diungkapakan oleh H. A. Simon [1987]. Kecerdasan buatan (artificial intelligence) merupakan kawasan penelitian, aplikasi dan instruksi yang terkait dengan pemrograman komputer untuk melakukan sesuatu hal yang dalam pandangan manusia adalah cerdas.

Rich and Knight [1991] mendefiniskan Kecerdasan Buatan (AI) sebagai sebuah studi tentang bagaimana membuat komputer melakukan hal-hal yang pada saat ini dapat dillakukan lebih baik oleh manusia. 


\section{Dempster Shafer}

Teori Dempster Shafer adalah suatu teori matematika untuk pembuktian berdasarkan belief functions and plausible reasoning (fungsi kepercayaan dan pemikiran yang masuk akal), yang digunakan untuk mengkombinasikan potongan informasi yang terpisah (bukti) untuk mengkalkulasi kemungkinan dari suatu peristiwa. Teori ini dikembangkan oleh Arthur P. Dempster dan Glenn Shafer.

\section{ANALISIS SISTEM}

\section{A. Analisis Jenis Kerusakan dan Gejala}

Sebelum mengetahui jenis kerusakan yang dialami oleh sebuah smartphone, perlu diketahui terlebih dahulu gejala-gejala yang ditimbulkan yang menyebabkan kerusakan pada smartphone tersebut. Sistem pakar ini mendiagnosa kerusakan pada smartphone dengan cara mencari jenis kerusakan berdasarkan gejala-gejala yang dialami sebuah smartphone menggunakan metode dempster shafer yang kemudian akan didapatkan kesimpulan berupa jenis kerusakan yang dialami beserta solusi yang harus dilakukan.

\section{B. Analisis Metode Dempster Shafer}

1. Membuat Tabel Gejala dan Menentukan Nilai Densitas

2. Membuat Tabel Jenis Kerusakan

3. Membuat Tabel Keputusan dan Relasi

4. Membuat Keterangan Basis Pengetahuan

5. Membuat Tabel Aturan atau Rule

6. Perhitungan Demster Shafer

\section{IV.PEMBAHASAN}

\section{A. Use Case Diagram}




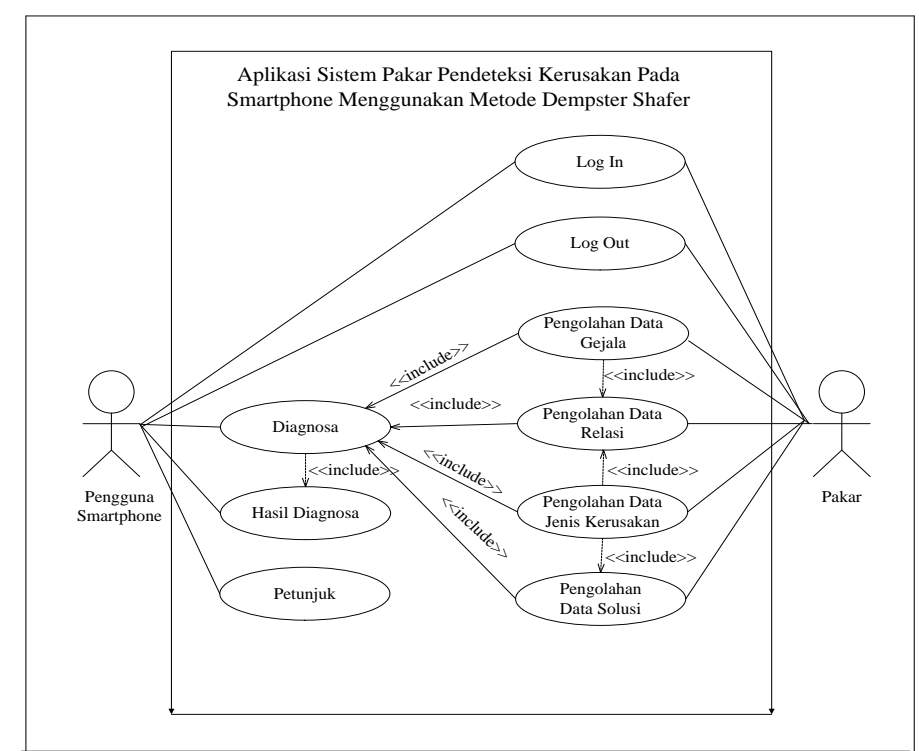

B. Activity Diagram Pengolahan Data Gejala

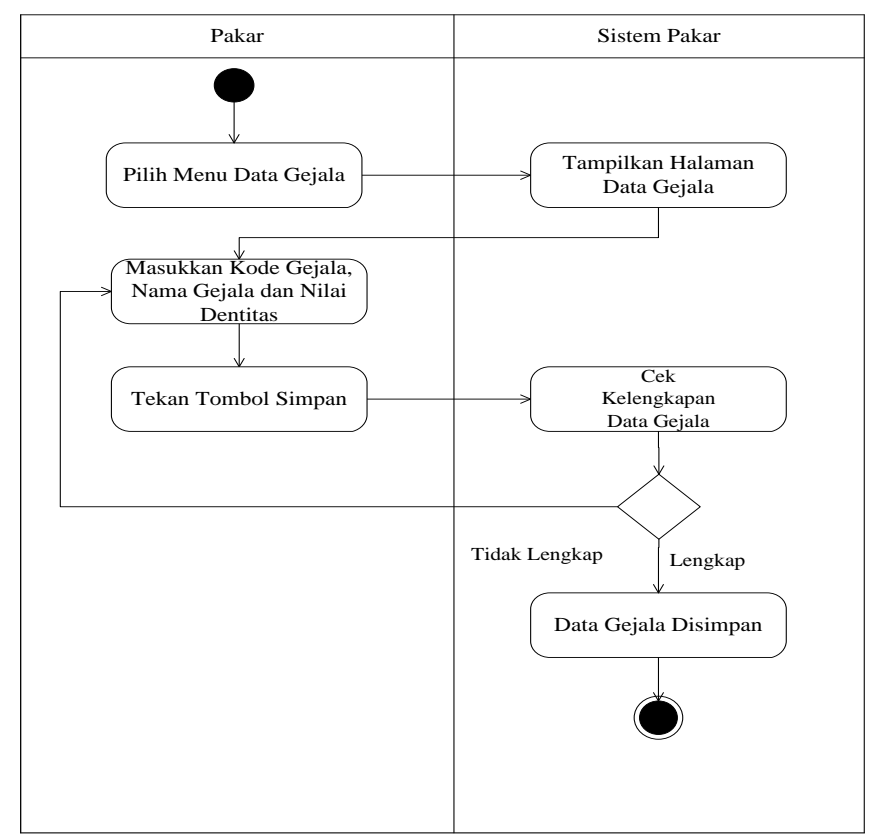

C. Sequence Diagram Pengolahan Data Gejala (Proses Ubah Data Gejala) 


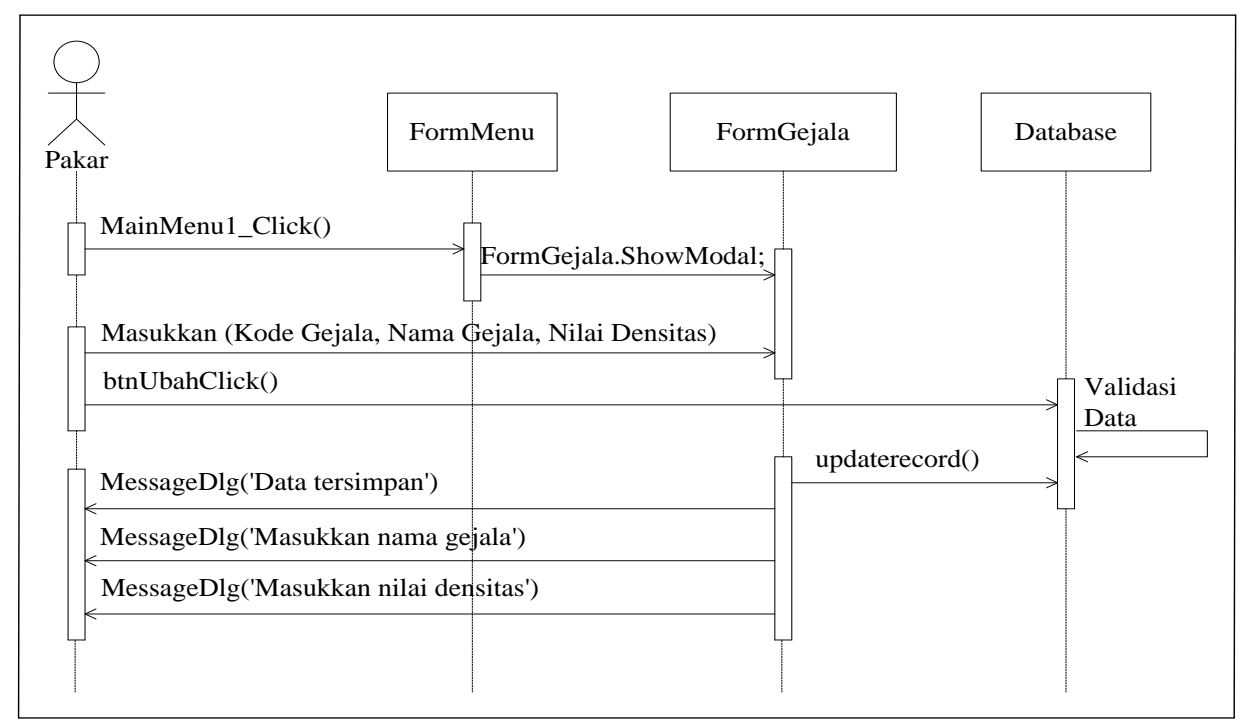




\section{Class Diagram}

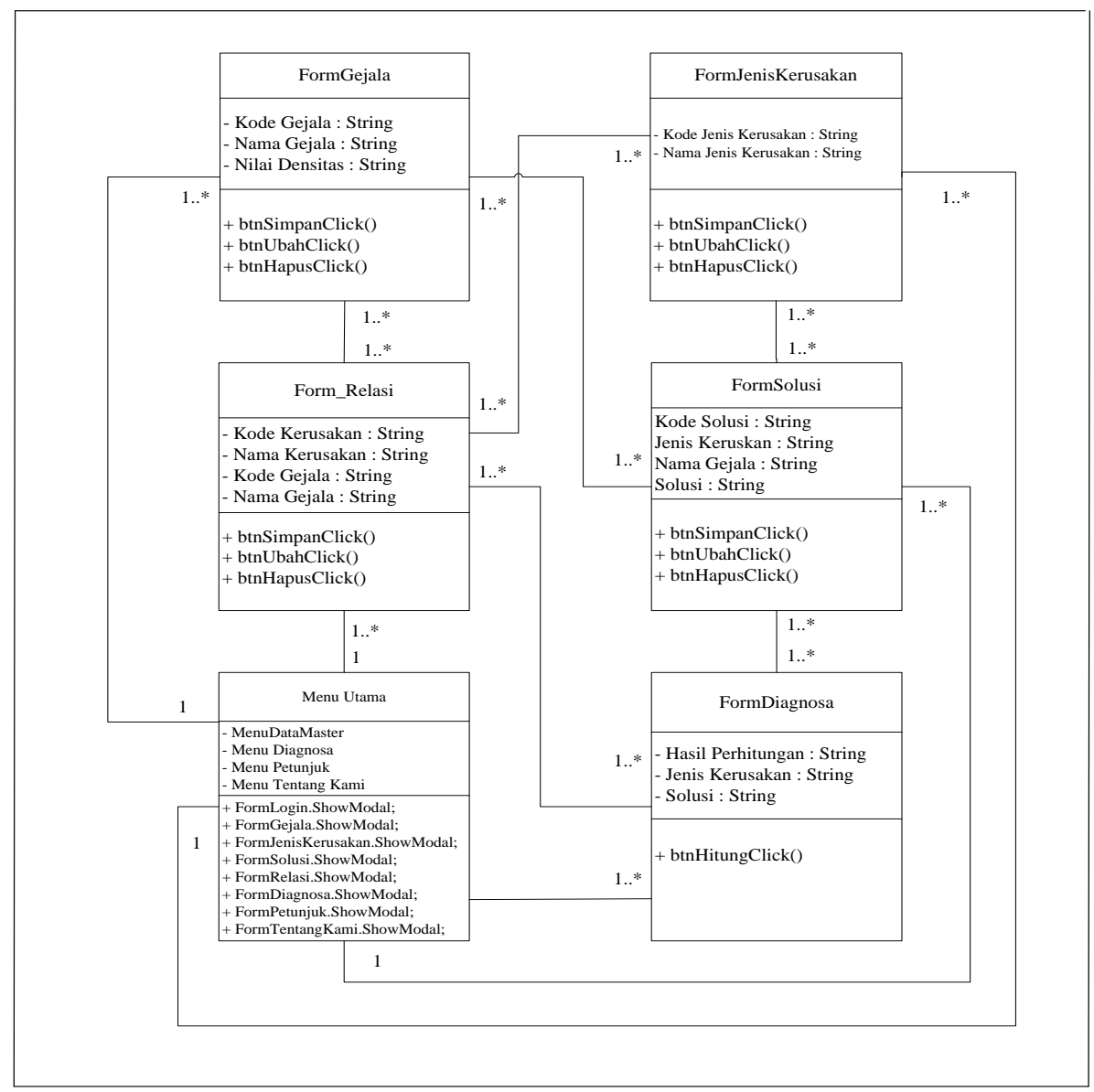

\section{KESIMPULAN DAN SARAN}

\section{A. Kesimpulan}

Setelah merancang dan membangun aplikasi sistem pakar pendeteksi kerusakan pada smartphone menggunakan metode dempster shafer, maka penulis mengambil beberapa kesimpulan adalah sebagai berikut:

1. Dengan adanya sistem pakar ini menambah informasi tentang pengetahuan dan pemahaman dalam pengenalan kerusakan pada smartphone.

2. Sistem pakar pendeteksi keusakan smartphone ini memudahkan pengguna smarphone mendapatkan informasi tentang jenis-jenis kerusakan pada smartphone.

3. Dengan adanya bantuan sistem pakar ini maka pengguna smartphone dapat mengetahui jenis kerusakan pada smartphone meraka dan mendapatkan solusi

\section{B. Saran dan Rekomendasi}


Setelah melakukan penelitian dan pengerjaan pembangunan aplikasi sistem pakar pendeteksi kerusakan pada smartphone menggunakan metode dempster shafer, terdapat beberapa saran yaitu :

1. Sistem pakar ini dapat dikembangkan untuk mendiagnosa kerusakan pada teknologi lain.

2. Aplikasi dapat dikembangkan menggunakan tampilan dan desain yang menarik.

3. Pada bagian hasil perhitugan di menu diagnosa dapat ditampilkan proses perhitungan dari awal sampai akhir menggunakan tabel aturan kombinasi.

\section{DAFTAR PUSTAKA}

Hendrayudi , VB 2008 untuk Berbagai Keperluan Programming, PT Elex Media Komputindo, 2009, Jakarta.

Departemen Pendidikan dan Kebudayaan, Kamus Besar Bahasa Indonesia, Balai Pustaka, Ed.2, 1991, Jakarta.

Wahyu Supriyanto dan Ahmad Muhsin, Teknologi Informasi Perpustakaan, Penerbit Kanisius, 2008, Yogyakarta.

M. Agus J. Alam, Belajar Sendiri Mengolah Database dengan Borland Delphi 7, PT Elex Media Komputindo, 2003, Jakarta.

Nugroho Adi, Analisa dan Perancangan Sistem Informasi dengan Metode Berorientasi Objek, Informatika, 2004, Bandung.

Jogiyanto HM, Analisis dan Desain Sistem Informasi. Andi, 2005 Yogyakarta.

Rika Rosnelly, Sistem Pakar Konsep dan Teori, Andi, Ed.1, 2005, Yogyakarta.

Kusrini, Sistem Pakar, Teori dan Aplikasi, Andi, Ed.1, 2006, Yogyakarta.

Sulistyohati, Aprilia dan Taufiq Hidayat, Aplikasi Sistem Pakar Diagnosa Penyakit Ginjal dengan Metode Dempster-Shafer, Seminar Nasional Aplikasi Teknologi Informasi, 2008, Yogyakarta.

Soni Daniswara dan Riyan, Mencari \& Memperbaiki Kerusakan Pada Handphone, Kawan Pustaka, 2004, Jakarta.

R. Wilman dan Riyan, Mengenali \& Mengatasi Kerusakan Software Handphone, Kawan Pustaka, 2006, Tangerang.

Kusrini, Aplikasi Sistem Pakar Menentukan Faktor Kepastian Pengguna dengan Metode Kuantifikasi Pertanyaan, Andi, Ed.1, 2008, Yogyakarta.

B. Herawan Hayadi, Sistem Pakar, Deepublish, 2016, Yogyakarta.

Arhami, Muhammad, Konsep Dasar Sistem Pakar, Andi, Ed.1, 2005, Yogyakarta.

Fowler, Martin, UML Distilled Edisi 3, Andi, Ed.1, 2005, Yogyakarta. 


\title{
PENILAIAN TINGKAT EFEKTIVITAS PENERAPAN KEAMANAN SISTEM INFORMASI MENGGUNAKAN ISO/IEC 27004:2009 DAN ISO/SNI 27001:2009 (STUDI KASUS DI STTI TANJUNGPINANG)
}

\author{
Ade Winarni, Linda Apriyanti \\ Adewina16@gmail.com, linda@sttindonesia.ac.id
}

\begin{abstract}
Abstrak
Sejak tahun 2014 STT Indonesia Tanjungpinang sudah menerapkan kebijakan SMKI, hal ini guna menunjang oprasional penerapan sistem informasi khususnya sistem informasi akademik dan keuangan (SIMAK), namun sampai saat ini belum dilakukan evaluasi terhadap penerapan SMKI tersebut.

Maka dari itu penelitian ini berfokus pada penilaian tingkat efektivitas penerapan keamanan sistem informasi menggunakan ISO/IEC 27004. Untuk memastikan bahwa kebijakan SMKI yang sudah diterapkan saat ini berjalan dengan baik. Tahap yang dilakukan dimulai dari pengukuran tingkat efektivitas penerapan keamanan sistem informasi, dari hasil pengukuran dilakukan penilaian tingkat efektivitas.

Jika dalam proses penelitian didapat kebijakan yang lemah, maka akan diberikan rekomendasi saran perbaikan baik berupa prosedur maupun standar oprating prosedur (SOP) guna meningkatkan keamanan informasi. Metodologi yang digunakan adalah fremework ISO/SNI 27001. Dalam penelitian ini peneliti mengharapkan adanya perbaikan kebijakan dan prosedur yang lemah guna meningkatkan keamanan informasi yang dapat menunjang oprasional dan proses bisnis.
\end{abstract}

Kata Kunci : SMKI, penilaian, pengukuran, efektivitas, ISO/IEC 27004, ISO/SNI 27001

\section{PENDAHULUAN}

Seiring dengan perkembangan teknologi dan informasi yang pesat dalam bidang pendidikan juga mempunyai persaingan yang semakin ketat demi mendukungnya proses bisnis yang berjalan, sehingga menuntut perguruan tinggi untuk melakukan terobosan dan perubahan agar dapat mengoptimalkan penggunaan Teknologi Informasi.STT Indonesia adalah perguruan tinggi yang telah memanfaatkan Teknologi Informasi, pengembangan pengelolaan dan pemanfaatan Sistem Informasi Terintegrasi. Sistem Informasi akademik (SIMAK) sebagai sistem utama yang terintegrasi dengan Sistem informasi Kerja Praktek dan Skripsi, Sistem Absensi, Ujian Saringan Mahasiswa Baru, Ujian Akhir Semester Online, E-library dan elearning. Sehingga dengan adanya layanan ini terselenggaranya pelayanan mahasiswa yang optimal dan tersedianya data dan informasi yang akurat melalui implementasi sistem informasi. 
Sistem Informasi Terintegrasi di STT Indonesia mulai diimplementasikan pada tahun 2011. Hasil wawancara dengan staf Pusat Pengolahan Data (PUSLAHTA) terdapat insiden dalam keamanan database yang pernah terjadi, diantaranya banyak pengguna yang mengakses terhadap sistem mengakibatkan banyak masalah yang timbul, terutama yang berkaitan dengan keamanan data yang mengakibatkan kehilangan dan kerusakan data.

Sehingga pada akhir tahun 2013, Ketua STT Indonesia menerbitkan Surat Keputusan tentang Kebijakan Keamanan Sistem Informasi. Namun sampai saat ini belum ada pengukuran tingkat efektivitas penerapan keamanan sistem informasi yang bisa menjamin bahwa kebijakan keamanan sistem informasi yang berjalan selama ini sudah mampu menangani masalah keamanan sistem informasi khususnya SIMAK di STT Indonesia Tanjungpinang.

\section{Keamanan Sistem Informasi}

Menurut SNI ISO/IEC 27001 : 2009 dikutif dari Iqbal (2013 :21) keamanan sistem informasi adalah penjagaaan kerahasiaan, integeritas dan ketersediaan informasi. Keamanan sistem informasi merupakan salah satu hal yang harus diperhatikan oleh perusahaan, kebocoran data dan informasi dan kegagalan sistem dapat menyebabkan kerugian baik di sisi finansial maupun produktifitas perusahaan. Keamanan informasi meliputi suatu mekanisme untuk mengontrol akses dan penggunaan database pada level obyek, keamanan informasi pada pengguna, dimana pengguna tersebut memiliki akses tertentu. Pengaturan mengenai keamanan informasi terutaman akan ditentukan berdasarkan seberapa jauh tingkat keamanan yang akan dibangun untuk informasi database. Tingkat keamanan informasi yang bergantung pada tingkat sensitifitas informasi dalam database, biasanya informasi yang tidak terlalu sensitif perlu pengaturan keamanan yang ketat untuk akses ke informai tersebut (mufadhol, 2009).

Seiring dengan perkembangan teknologi, pengelolaan keamanan database semakin lama menjadi pekerjaan yang semakin sulit dan menantang. Pihak yang bertanggung jawab terhadap sistem keamanan database harus dapat memastikan tiga hal utama dalam keamanan database yaitu kerahasiaan (confidentiality), integritas (Integrity) dan ketersediaan (availability).

\section{SistemManajemenKeamananInformasi (SMKI)}


Sistem Manajemen Keamanan Informasi (SMKI) merupakan bagian dari manajemen secara keseluruhan. Informasi dipandang sebagai aset penting sama seperti aset perusahaan lainnya, karena itu bagi perusahaan adalah hal yang penting untuk menggunakan pendekatan risiko dalam mengelola aset tersebut (ISO 27001: 2005).

Model PLAN - DO - CHECK - ACT (PDCA) diterapkan terhadap struktur keseluruhan proses information security management system ISMS/SMKI. Berikut adalah tahapan-tahapan PDCA:

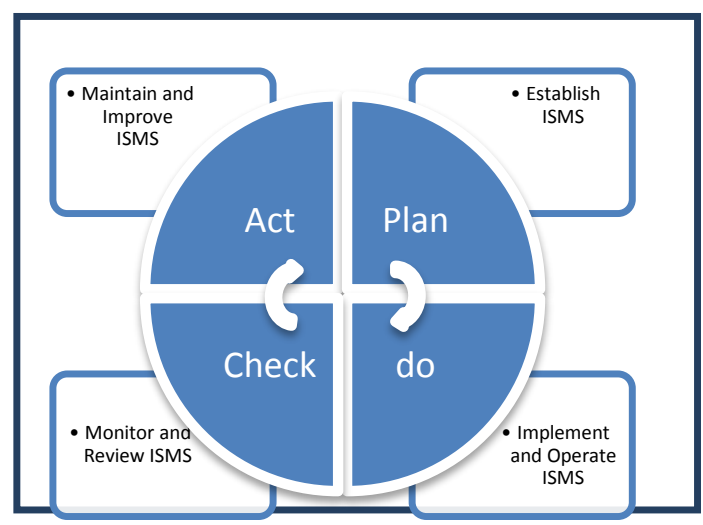

Gambar 1. Proses SMKI/ ISMS

\section{KerangkaPenelitian}

Kerangka penelitian adalah langkah-langkah sistematis atau sekumpulan metode yang digunakan untuk menyelesaikan suatu permasalahan. Tahapan yang dilakuakan dimulai dengan melakukan wawancara dengan unit bagian yang terkait yaitu denagn ketua STT Indonesia Tanjungpinang, ketua pusat pengolahan data (PUSLAHTA) dan pusat pengelolaan komputer (PUSKOM) dan melakukan studi pustaka terkait keamanan sistem informasi, dari sini kemudian ditentukan ruang lingkup yang akan dijadikan topik penelitian yaitu keamanan sistem informasipada SIMAK lebih sepesifiknya adalah penilaian tingkat efektivitas penerapan SMKI. Langkah selanjutnya adalah mengumpulkan data berupa bukti dan temuan yang berkaitan dengan topik penelitian, dari data yang diperoleh dilkuakan pengukuran tingkat efektivitas penerapan SMKI dengan menggunakan ISO 27004 dan dari hasil pengukuran dilakukan penilaian tingkat efektivitas dengan menggunakna fremwork ISO 27004. Dari hasil penilaian yang dilkukan dibuatkan saran perbaikan terutama untuk point yang dianggap rawan yaitu 
dengan penilaian paling rendah. Perancangan panduan peningkatan penerapan SMKI pada tahap ini menggunakan ISO / SNI 27001. Berikut adalah gambar dari kerangka penelitia :

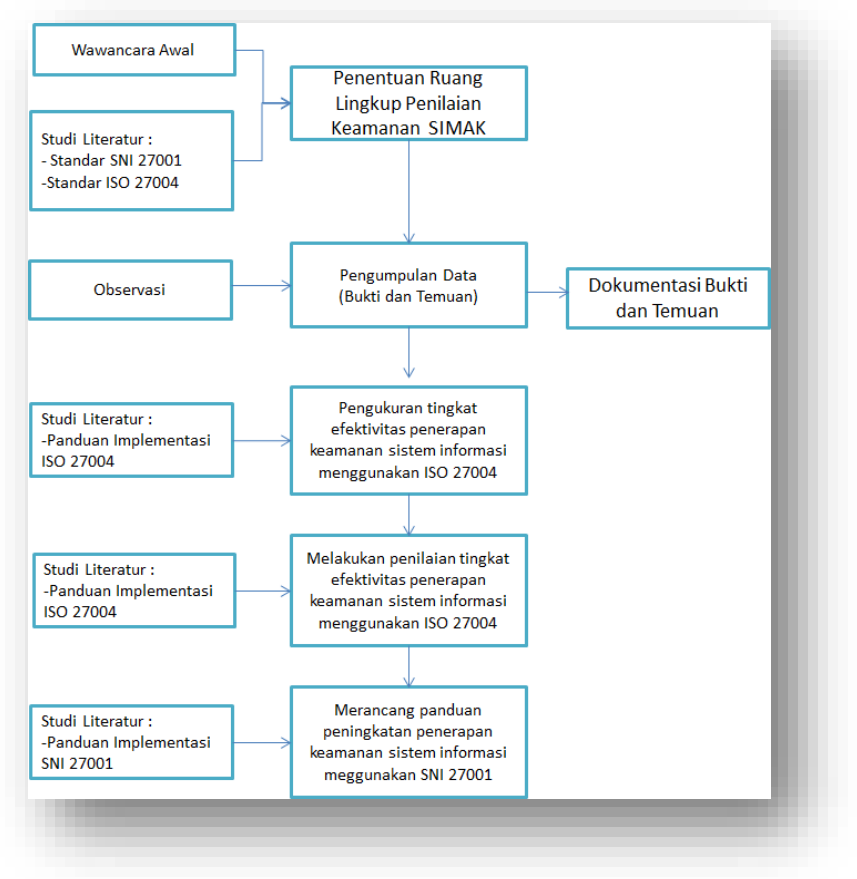

Gambar 2. Kerangka Penelitian

\section{Pengukurantingkatefektivitas}

Berdasarkan penerapan SMKI di STT Indonesia Tanjungpinang, maka peneliti melakukan pengukuran tingkat efektivitas dengan menggunakan ISO/IEC 27004 klausul B8yaitu pengukuran operasi. Pengukuran oprasi keamanan informasi melibatkan kegiatan yang penting untuk memastikan bahwa hasil pengukuran dikembangkan memberikan informasi yang akurat berkaitan dengan efektivitas sebuah diimplementasikan SMKI.

Berdasarkan hasil kuesioner yang disebarkan kepada responden, maka dapat diketahui pernyataan responden mengenai tingkat efektivitas penerapan SMKI.Adapun kriteria penilaian sebagai berikut:

Tabel 1 : Kriteria Penilaian 


\begin{tabular}{|l|l|}
\hline Kriteria penilaian & Skor \\
\hline Sangat Efektif & 5 \\
\hline Efektif & 4 \\
\hline Cukup Efektif & 3 \\
\hline Kurang Efektif & 2 \\
\hline Tidak Efektif & 1 \\
\hline
\end{tabular}

\section{Penilaian Tingkat Efektivitas}

Penilaian tingkat efektivitas terhadap penerapan SMKImerupakan salah satu indikator kinerja bagi pelaksanaan suatu kegiatan yang telah ditetapkan untuk menyajikan informasi tentang seberapa besar pencapaian sasaran atas target. Penilaian efektivitas penerapan SMKI dikategorikan efektif atau tidak apabila interval nilai dimulai dari angka $1.00-5.00$. Untuk penilaian tingkat efektivitas keamanan sistem informasi manajemen akademik dan keuangan (SIMAK) STT indonesia Tanjungpinang, apabila hasilnya menunjukan nilai dengan interval yang semakin besar dapat dikatakan bahwa semakin efektif, demikian sebaliknya semakin kecil nilai interval hasilnya maka menunjukan semakin tidak efektif.Berikut adalah kriteria penilaian tingkat efektivitas berdasarkan hasil pengukuran tingkat efektivitas :

Tabel 2 : Penilaian tingkat efektivitas

\begin{tabular}{|c|c|}
\hline Dampak & Keterangan \\
\hline Sangat & Dampak tidak \\
\hline $\begin{array}{l}\text { Efektif } \\
\qquad(5)\end{array}$ & $\begin{array}{l}\text { berpengaruh pada } \\
\text { operasional dan bisnis }\end{array}$ \\
\hline $\begin{array}{c}\text { Efektif } \\
\text { (4) }\end{array}$ & $\begin{array}{l}\text { Dampak tidak } \\
\text { terlalu berpengaruh } \\
\text { pada operasional dan } \\
\text { bisnis }\end{array}$ \\
\hline Cukup & Dampak \\
\hline $\begin{array}{c}\text { Efektif } \\
\text { (3) }\end{array}$ & $\begin{array}{l}\text { berpengaruh } \\
\text { operasional }\end{array}$ \\
\hline
\end{tabular}




\begin{tabular}{|c|c|}
\hline $\begin{array}{c}\text { Kurang } \\
\text { Efektif } \\
(2)\end{array}$ & \multicolumn{2}{|c|}{$\begin{array}{c}\text { Dampak } \\
\text { berpengaruh pada } \\
\text { operasional dan bisnis }\end{array}$} \\
\hline Tidak Efektif & \multicolumn{1}{|c|}{ Dapat mematikan } \\
\hline$(1)$ & bisnis \\
\hline
\end{tabular}

\section{Hasil Pengukuran Efektivitas SMKI}

Hasil pengukuran tingkat efektivitas SMKI yang dilakukan di STT Indonesia Tanjungpinang berada pada nilai2,13 yaitu pada tingkat Kurang Efektif. sesuai dengan interval nilai yang digunakan oleh peneliti pada bab 3(tiga) Metodelogi Penelitian.

Tabel 3 :Interval Penilaian Jawaban Responden

\begin{tabular}{|c|l|}
\hline Interval & Kriteria \\
\hline $4,20-$ & Sangat Efektif \\
5,00 & \\
\hline $3,40-4,19$ & Efektif \\
\hline $2,60-3,39$ & Cukup Efektif \\
\hline $1,80-2,59$ & Kurang Efektif \\
\hline $1,00-$ & Tidak Efektif \\
1,79 & \\
\hline
\end{tabular}

Setelah mengetahui hasil pengukuran yang berada pada nilai 2,13 selanjutnya adalah melakukan perhituanga gap terhadap masing-masing point pertanyaan sesuai dengan target organisasi yaitu pada nilai 3,5 (Efektif) pada tahun 2017.

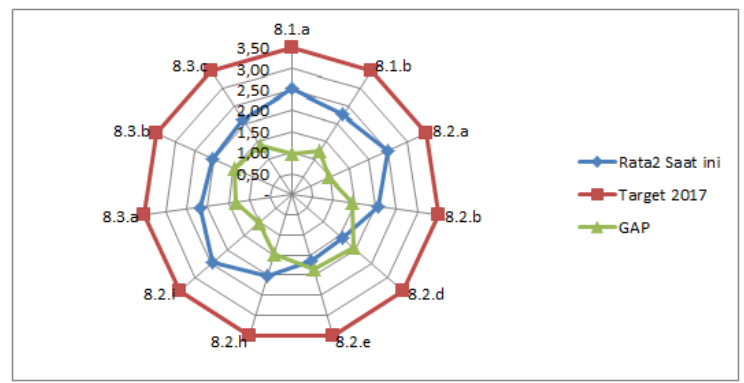

Gambar 3. Diagram radar perhitungan gap terhadap target 


\section{Penilaian Tingkat Efektivitas}

Penilaian tingkat efektivitas penerapan SMKI berdasarkan hasil pengukuran pada point (4.4), adalah dengan melakukan analisis data dari identifikasi kesenjangan antra hasil pengukuran yang diharapkan dan aktual dari hasil implementasi SMKI.Setelah dilakukan pengukuran tingkat efektivitas penerapan SMKI di STT Indonesia Tanjungpinang berada pada nilai 2,13 dimana itu adalah posisi "Kurang Efektif", sedangkan target yang ingin di capai adalah pada nilai 3,5 yaitu "Efektif", agar proses operasional dapat terus berjalan dan bisnis dapat terus berkembang. Untuk merealisasikan hal tersebut perlu dibuatkan alisis hasil pengukuran tingkat efektivitas SMKI dengan membuat dokumen kontrol dapat digunakan disetiap insiden yang terjadi dalam implementasi SMKI. Dokumen kontrol dipergunakan untuk menindak lanjuti ketika ada insiden terjadi, hasil dari analisis dikomunikasikan dengan pimpinan. Berikut adalah analisis hasil pengukuran efektivitas SMKI :

Tabel 5 : Pengukuran efektivitas SMKI

\begin{tabular}{|c|c|c|c|c|}
\hline \multirow{2}{*}{ Skala } & \multirow{2}{*}{ Dampak } & \multicolumn{3}{|c|}{ Indikator } \\
\hline & & Uraian & Identifikasi & Kontrol \\
\hline 5 & $\begin{array}{l}\text { Sangat } \\
\text { Efelktif }\end{array}$ & $\begin{array}{l}\text { Terjadi } \\
\text { peninglsatan } \\
\text { terhadisp } \\
\text { implemnetasi } \\
\text { SMIKI secara } \\
\text { signifilsan }\end{array}$ & $\begin{array}{l}\text { Insiden jarang aelcali } \\
\text { terjadi, masalah dapat } \\
\text { diselesaikan dengan } \\
\text { mudiah dan cepat }\end{array}$ & $\begin{array}{l}\text { a. Tidak menjadi } \\
\text { folkus } \\
\text { pemeriksasen } \\
\text { b. Tetsp melakukan } \\
\text { pendokumentasia } \\
\text { n secara berksala }\end{array}$ \\
\hline 4 & Efolstif & $\begin{array}{l}\text { Terjadi } \\
\text { peninglsatan } \\
\text { terhadas } \\
\text { implemnetasi } \\
\text { SMKI, namun } \\
\text { tidak signifikan }\end{array}$ & $\begin{array}{l}\text { Insiden seselcali terjadi } \\
\text { dan ada usaha perbailsan, } \\
\text { tetapi ada kemungkinan } \\
\text { aksan mengalaminya di } \\
\text { masa depan. Sehingga } \\
\text { strategi asat ini harus } \\
\text { mengatsai insiden yang } \\
\text { terjadi }\end{array}$ & $\begin{array}{l}\text { a. Tetsp menjadi } \\
\text { fokus } \\
\text { permeriksasn } \\
\text { b. Tetsp melakukan } \\
\text { pendokumentasia } \\
\text { n secara berkala }\end{array}$ \\
\hline 3 & $\begin{array}{l}\text { Culsup } \\
\text { Efektif }\end{array}$ & $\begin{array}{l}\text { Terjadi } \\
\text { peningkatan } \\
\text { terhadap } \\
\text { implemnetasi } \\
\text { SMKI, namun } \\
\text { hanya di bagian } \\
\text { tertentu }\end{array}$ & $\begin{array}{l}\text { Insiden berlangsung terus } \\
\text { menerus namun sudah adi } \\
\text { kesadaran untuk } \\
\text { melakuksan usaha } \\
\text { perbaikan. Altematif } \\
\text { mungkin diperluksan dan } \\
\text { harus mempertimbangkan } \\
\text { tindakan mitigasi }\end{array}$ & $\begin{array}{l}\text { Walaupun tidals } \\
\text { menjadi folsus, } \\
\text { tetspi harus ada } \\
\text { perhatian yang } \\
\text { cukup } \\
\text { b. Menjadi folus } \\
\text { pemeriksan } \\
\text { walsupun tidak } \\
\text { terlalu mendalam } \\
\text { c. Tindakan mitigasi } \\
\text { berpedoman pada } \\
\text { prosedur }\end{array}$ \\
\hline 2 & $\begin{array}{l}\text { Kurrang } \\
\text { Efektif }\end{array}$ & $\begin{array}{l}\text { Tidiak ada } \\
\text { peningkatan } \\
\text { terhadsp } \\
\text { implemnetasi } \\
\text { SMIKI yang } \\
\text { aignifilsan }\end{array}$ & $\begin{array}{l}\text { Insiden terus menerus dan } \\
\text { sedikit ada usaha } \\
\text { perbaiksan. Altematif alsan } \\
\text { diperluksan dam } \\
\text { menentulvan tindalsan } \\
\text { mitigasi yang dibutuhlsan }\end{array}$ & $\begin{array}{l}\text { a. Menjadi folkus } \\
\text { permeriksaan } \\
\text { b. Melakukan } \\
\text { perbaiksm sesuai } \\
\text { dengan prosedur } \\
\text { untuk mengurangi } \\
\text { insiden }\end{array}$ \\
\hline 1 & $\begin{array}{l}\text { Tidak } \\
\text { Bfektif }\end{array}$ & $\begin{array}{l}\text { Tidalk ada } \\
\text { peningkatan } \\
\text { terhadisp } \\
\text { implementasi } \\
\text { SMIKI }\end{array}$ & $\begin{array}{l}\text { Insiden berlangsung terus } \\
\text { menerus dan tidak ada } \\
\text { usaha perbaikan sama } \\
\text { selsali. Altematif sangat } \\
\text { diperlukan dan tindaksan } \\
\text { mitigasi harus segera } \\
\text { dilakuksm }\end{array}$ & 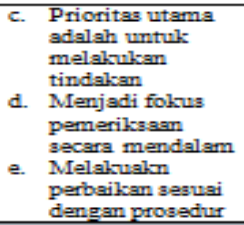 \\
\hline
\end{tabular}

9. RekapAnalisistingkatkematangan berdasarkan ISO /SNI 27001 klausul A.8, A.9, A.11 dan A.12 
Setelah melakukan analisis dari setiap klausul yang digunakan yaitu klausul A.8 Keamanan Sumber daya Manusia, A.9 Keamanan fisik dan lingkungan, A.11 Pengendalian akses, A.12 Akuisisi, pengembangan dan pemeliharaan sistem informasi. Didapat bahwa tingkat kematangan saat ini rata-rata adalah 2,4 dimana masih dibawah tingkat kematangan yang diharapkan yaitu 3,5 kesenjangan tersebut digunakan sebagai dasar dalam mengembangkan strategi pengembangan penerapan keamanan sistem informasi selanjutnya. Hasil dan laporan temuan digunakan sebagai rekomendasi saran untuk perbaikan kontrol keamanan sistem informasi berikutnya.

Tabel 4 : Tabel Analisis tingkat kematangan berdasarkan klausul A.8, A.9, A.11 dan A.12

\begin{tabular}{|c|l|c|c|c|}
\hline No & \multicolumn{1}{|c|}{ Kontrol } & Saat ini & Target 2017 & GAP \\
\hline 1 & $\begin{array}{l}\text { A.8 Keamanan Sumber daya } \\
\text { Manusia }\end{array}$ & 2,6 & 3,5 & 0,9 \\
\hline 2 & A.9 Keamanan fisik dan lingkungan & 2,5 & 3,5 & 1,0 \\
\hline 3 & A.11 Pengendalian akses & 2,3 & 3,5 & 1,2 \\
\hline 4 & $\begin{array}{l}\text { A.12 Akuisisi, pengembangan dan } \\
\text { pemeliharaan sistem informasi }\end{array}$ & 2,3 & 3,5 & 1,2 \\
\hline & RATA-RATA & 2,4 & 3,5 & 1,1 \\
\hline
\end{tabular}

Berikut adalah diagram radar berdasarkan tabel 4.16analisis tingkat kematangan berdasarkan klausul A.8, A.9, A.11 dan A.12

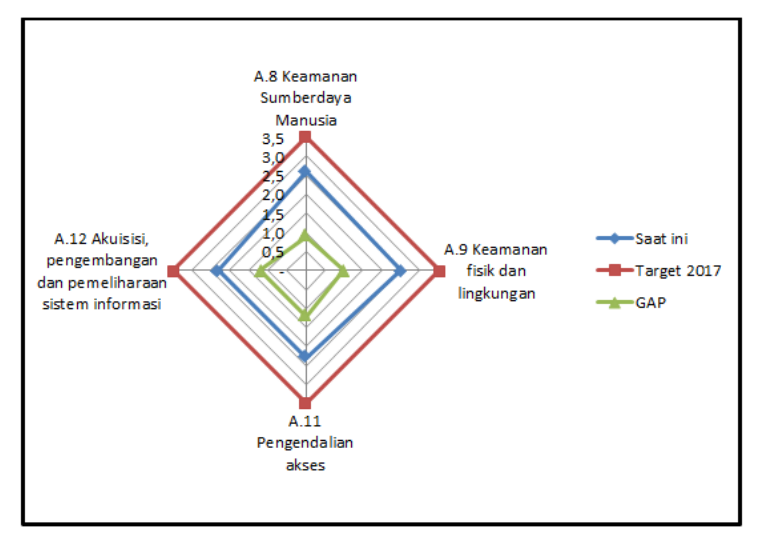

Gambar 4 :Tingkat kematangan berdasarkan klausul A.8, A.9, A.11 dan A.12

\section{Rekomendasi Perbaikan}

Rekomendasi terhadap tingkat kematangan yang diperoleh mengimplementasikan kontrolkontrol keamanan sesuai dengan pencapaian nilai rata-rata untuk diberikan saran perbaikan 
yang dirancang untuk menjamin bahwa tujuan dan target dapat tercapai, sedangkan insiden yang merugikan dapat dicegah, dideteksi dan dievaluasi secara berkala.

\section{A.8 Keamanan Sumberdaya Manusia}

Rekomendasi :

a. Melakukan pemeriksaan latar belakang dari calon karyawan TI

b. Melakukan penyesuaian kontrak perjanjian kerja berdasarkan kebijakan keamanan informasi

c. Melakukan pembinaan dengan melaksanakan pelatihan tentang kepedulian menjaga keamanan informasi

d. Memberikan penugasan dan memperhatikan shering responsibilitas, berdasarkan bebankerja, sehingga karyawan dapat bekerja dengan penuh tanggung jawab

2. A.9 Keamananfisikdanlingkungan

Rekomendasi :

a. Memiliht tempat lokasi penyimpanan dan backup yang terpisah dari ruang server.

b. Membuat dokumentasi karyawan yang diperbolehkan masuk keruang server untuk memastikan hanya karyawan yang berwenang yang mempunyai hak akses masuk.

c. Mengkomunikasikan mengenai standard dan prosedur mengenai keamanan sistem informasi yang diterapkan sehingga bias memberikan solusi untuk pengadaan dan pemeliharaan peralatan.

\section{A.11 Pengendalianakses}

Rekomendasi :

a. Membuat prosedur pendaftaran dan pembatalan dalam pemberian dalam pemberian dan pencabutan akses terhadap seluruh layanan dan system informasi.

b. Membuat prosedur penggantian password secarareguler.

c. Menambahkan pasilitas tingkat kerumitan dari password, (Tingkat rendah, sedang, rumit)

d. Memberikan pelatihan dan sosialisai agar setiap karyawan menyadari pentingnya pengendalian akses 
4. A.12 Akuisisi, pengembangandanpemeliharaansisteminformasi

Rekomendasi :

a. Membuat prosedur pemantauan penggunaan fasilitas pengolahan system informasi

b. Membuat dokumentasi hasil pemantauan dan pengawasan yang diperlukan berdasarkan tingkat insiden.

c. Menggunakan enkripsi pada informasi yang dianggap sangat rahasia

d. Melakukan monitoring, evaluasi dan perbaikan secara berkala untuk tercapainya target keamanan system informasi

e. Memberikan pelatihan dan sosialisai agar setiap karyawan menyadari pentingnya keamanan sistem informasi

\section{SIMPULAN DAN SARAN}

\section{Kesimpulan :}

Berdasarkan penelitian yang telah dilakukan dapat disimpulkan beberapa hal, yaitu:

1. Pengukuran tingkat efektivitas penerapan SMKI di STT Indonesia Tanjungpinang menghasilkan saran perbaikan untuk peningkatan tingkat efektivitas SMKIterhadap SIMAK, dalam melakukan pengukuran dimulai dengan melakukan wawancara untuk menentukan dokumen-dokumen yang diperlukan. Langkah pengukuran dilakukan dengan melakukan kuisioner, pengukuran dan penilain tingkat efektivitas.

2. Framework ISO 27004 dan ISO 2700 dipilih karena Indonesia meupakan member ISO melalui BSN. ISO 27004 dan ISO 27001 merupakan metoda pengukuran tingkat efektivitas penerapan SMKI yang dapat diterapkan pada perguruan tinggi. Pengukuran tingkat efektivitas penerapan SMKI memberikan gambaran mengenai hasil penilaian yang dianggap krusial dan memerlukan penanganan secara khusus dan prioritas. Dimana pembuat kebijakan dapat membuat perencanaan strategis untuk menjagakepercayaan, operasional dan proses bisnis tetap berlangsung.

3. Berdasarkan hasil pengukuran tingkat efektivitas, saat ini berada pada nilai 2,13 (Kurang Efektif) dengan nilai gap 1,37 dari target organisasi pada tahun 2017 yaitu 3,5 (Efektif).

4. Analisis hasil pengukuran tingkat efektivitas pada tingkat Kurang Efektif yaitu terjadi peningkatan terhadap implemnetasi SMKI, namun hanya di bagian tertentu. Dimana insiden 
berlangsung terus menerus namun sudah ada kesadaran untuk melakukan usaha perbaikan. Alternatif mungkin diperlukan dan harus mempertimbangkan tindakan mitigasi.

\section{Saran :}

Berdasarkan hasil penelitian yang dilakukan, dapat dikemukakan beberapa saran yang dapat dipertimbangkan untuk ditindak lanjuti, yaitu:

1. Tingkat keamanan sistem masih pada tingkat cukup efektif sehingga harus ditingkatkan sesuai dengan target organisasi yaitu tingkat efektif.

2. Menyempurnakan SOP untuk meningkatkan keamanan sistem informasi yang dapat mendukung kelancaran pelayanan SIMAK di STT Indonesia Tanjungpinang sehingga bisa meningkatkan proses bisnis.

3. Rekomendasi saran perbaikan dan prosedur sehingga dapat meningkatkan keamanan informasi. Yaitu keamanan sumberdaya manusia, keamanan fisik dan lingkungan, pengendalian akses, akuisisi, pengembangan dan pemeliharaan system informasi, terutama yang memiliki hasil penilaian yang dianggap krusial yaitu pengendalianakses , akuisisi, pengembangandanpemeliharaansisteminformasi

\section{DAFTARPUSTAKA}

[1]Ahmad, Deni, Dirgahayu, Teduh \& Hendrik, 2013. "Manajemen Risiko Sistem Informasi Akademik pada Pergutuan Tinggi Menggunakan Actave Allegro" Yogyakarta : SNATI (Seminar Nasional Aplikasi Teknologi Informasi).

[2] Azwar, Saifuddin.(2000). Reliabilitas dan Validitas. Yogyakarta : Pustaka Belajar

[3] Djojosoedarso, Soeisno, 2000. "Prinsip-prinsip Manajemen Resiko dan Asuransi”. Jakarta : Salemba 4

[4] Hidayat, M. N, 2011. "Kajian Tata Kelola Keamanan Informasi Berdasarkan Information Scurity (ISMS) ISO 27001:2005 Untuk Outsourting Teknologi Informasi Pada PT Kereta Api Indonesia (Persero)". Jakarta : Program Studi Magister Teknologi Informasi Fasikom UI.

[5] ISO/SNI 27001:2009(E)

[6] ISO/IEC 27004:2009(E)

[7] Jogiyanto, Hartono, 2005. “Analisis \& Desain Sistem Informasi Pendekatan Terstruktur Teori dan Praktek Aplikasi Bisnis. Andi Yogyakarta. 
[8] Maryuni, Bekti, 2013. "Mengukur Keamanan Informasi : Studi Komparasi ISO 27002 dan NIST 800-55" Yogyakarta : SENTIKA2013.

[9] M, Andre \& Wajong R, 2012. "Information security managemen system using ISO 27000" Jakarta : Universitas Keristen Indonesia.

[10] Rahardjo, Budi, 2005, "Keamanan Sistem Informasi Berbasis Internet ”Jakarta : PT Insan Infonesia - Bandung \& PT INDOCISC .

[11] Richardus Eko Indrajit.2000. "Konsep Dasar Manajemen Sistem Informasi dan Teknologi Informasi”. Jakarta : Elex Media Komputindo

[12] Syafrizal, M, 2007 ISO 17799. "Standar Sistem Manajemen Keamanan Informasi" Seminar Nasional Teknologi 2700 (SNT 2007)

[13] Soenardi, Idbal \& Ichsan, M, 2013. “Analisis Kematangan Sistem Manajemen Keamanan Informasi Badan Pendidikan dan Pelatihan Keuangan Diukur Menggunakan Indeks Keamanan Informasi” Jakarta : Kementrian Keuangan RI.

[14] Sugiyono, 2006, Statistika Untuk Penelitian, Cetakan Ketujuh, Bandung: CV. Alfabeta.

[15] Sugiyono (2004), Metode Penelitian Bisnis, CV. Alfabeta, Bandung.

[16] Zulfikar, Reza, 2013. "Audit Kepatuhan Keamanan Informasi [Karya Akhir]" Jakarta : Program Studi Magister Teknologi Informasi UI. 